\title{
Incidence Trends of Diabetic Ketoacidosis in Children and Adolescents with Type 1 Diabetes in British Columbia, Canada
}

Kung-Ting Kao, MBChB, DMedSc ${ }^{1,{ }^{*}}$ Nazrul Islam, MBBS, MSc, MPH, PhD $2,{ }^{*,+}$ Danya A. Fox, MD, MPH${ }^{1}$ Shazhan Amed, MD, MScPH ${ }^{1}$

${ }^{1}$ Divisions of Diabetes and Endocrinology, British Columbia Children's Hospital and

Department of Pediatrics, University of British Columbia, Vancouver, Canada

${ }^{2}$ MRC Epidemiology Unit, University of Cambridge, Cambridge, UK

${ }^{*}$ Contributed equally.

${ }^{\dagger}$ Current address: Nuffield Department of Population Health, Big Data Institute, University of Oxford, Oxford, United Kingdom.

Address for correspondence and reprints: Dr. Shazhan Amed

Endocrinology and Diabetes Unit, Room K4-212,

British Columbia Children's Hospital,

4480 Oak Street, Vancouver BC V6H 3V4,

Canada.

Phone: 1-604-8752117

Fax: 1-604-8753231

Email: samed@cw.bc.ca

Funding: Funded by Diabetes Canada (formerly Canadian Diabetes Association) (OG- 3-144488-SA). All inferences, opinions, and conclusions drawn in this article are those of the authors, and do not reflect the opinions or policies of the Population Data BC's Data Steward(s). The authors declare no conflicts of interest.

Portions of this study were presented at the American Diabetes Association Scientific Sessions, June 7-11, 2019, San Francisco, CA.

Financial disclosure: The authors have indicated they have no financial relationships relevant to this article to disclose.

Conflict of Interest: None 


\section{ABSTRACT \\ Objectives}

To estimate the 11-year incidence trend of diabetic ketoacidosis (DKA) at and after the diagnosis of type 1 diabetes.

\section{Study design}

A retrospective cohort study using a population-based administrative cohort diagnosed with type 1 diabetes at <20 years of age from 2002 to 2012 in British Columbia, Canada. DKA at (1 episode per individual) and DKA after (multiple episodes per individual) the diagnosis of diabetes were defined as DKA occurring $\leq 14$ days or $>14$ days, respectively, from diagnosis, identified using International Classification of Diseases, 9th and 10th editions codes. Incidence rate ratios were estimated using Poisson regression and DKA trends using Joinpoint regression analyses.

\section{Results}

There were 1519 individuals (mean age at first-DKA, $12.6 \pm 5.9$ years; $50 \%$ male) with $\geq 1$ DKA episode identified. Of 2615 incident cases of type 1 diabetes, there were 847 (32.4\%; mean age, $9.9 \pm 4.8$ years; $52 \%$ male) episodes of DKA at the diagnosis of diabetes. Among prevalent cases of type 1 diabetes (1790 cases in 2002 increasing to 2264 in 2012), there were 1886 episodes of DKA after the diagnosis of diabetes (mean age at first DKA, $15.7 \pm 5.2$ years). The rates per 100 person-years of DKA at diabetes diagnosis (ranging from 24.1 in 2008 to 37.3 in 2006) and DKA after diabetes diagnosis (ranging from 4.9 in 2002 to 7.7 in 2008) remained stable. Females showed a $67 \%$ higher rate of incidence of DKA after the diagnosis of diabetes compared with their male counterparts (incidence rate ratio, 1.67; $95 \% \mathrm{Cl}, 1.50-1.86 ; \mathrm{P}<.001$ ), adjusted for the temporal trend by fiscal year. Younger age at diagnosis ( $<5$ years) was associated with a greater risk of DKA at the time of diabetes diagnosis and older children ( $\geq 10$ years) had a greater risk of DKA after the diagnosis of diabetes.

\section{Conclusions}

The risk of DKA at the time of diagnosis of diabetes was greater with younger age and the risk of DKA after the diagnosis of diabetes was higher in females and older children and youth.

Keywords: type 1 diabetes; diabetic ketoacidosis; incidence; children; adolescents; pediatric

Abbreviations: APC: Annual percent change; BC: British Columbia; DKA: Diabetic ketoacidosis; ICD: International Classification of Diseases; IRR: Incidence rate ratio 


\section{Introduction}

Type 1 diabetes affects more than one-half of a million children $<15$ years of age worldwide. ${ }^{1}$ In the Canadian province of British Columbia (BC), the number of youth $<20$ years of age with type 1 diabetes is projected to increase from roughly 2200 in 2012 to 2600 by $2020 .^{2}$ Diabetic ketoacidosis (DKA) is an acute complication of type 1 diabetes and is the leading cause of mortality in youth with type 1 diabetes. ${ }^{3}$ Even a single episode of DKA in young children is associated with acute kidney injury and significant cognitive deficits including lower IQ scores, poorer cognitive performance, and altered brain growth. ${ }^{4,5}$

DKA is caused by severe insulin deficiency in either previously undiagnosed patients with type 1 diabetes or in individuals with known diabetes who deliberately or inadvertently take insufficient amounts of insulin..$^{6,7}$ However, DKA at and after the diagnosis of type 1 diabetes are both preventable by early recognition of symptoms, timely diagnosis, and adequate insulin management.

Since the Diabetes Complications and Control Trial in the early 1990s, there have been considerable advances in diabetes management (ie, rapid acting insulin analogues, insulin pumps, and continuous glucose monitoring systems) to help patients achieve optimal glycemic control. However, despite these advances, DKA rates remain high internationally, and are rising in the US. $8,9,10,11,12,13,14,15$

There are limited published Canadian data on DKA trends in children and these data do not separately describe DKA at vs after the diagnosis of diabetes. In the province of Ontario, DKA rates (at/after diagnosis combined) remained stable at 28\% to 39\% between 1991 and 1999. ${ }^{10}$ A study from the province of Quebec found that the rate of DKA at diagnosis of diabetes increased from 22\% in 2001 to 30\% in 2014, but the rates of DKA after diagnosis were not examined. ${ }^{16}$ The factors contributing to the development of DKA at vs after diagnosis of type 1 diabetes are likely to be distinctive, and therefore it is of value to understand them as separate events to design effective preventative interventions. The objective of this study was to describe 11-year trends in the incidence of DKA at and after the diagnosis in a population-based cohort of individuals diagnosed with type 1 diabetes 
during childhood in the Canadian province of BC. We hypothesized that there would be an increasing trend for DKA at diagnosis of diabetes in BC over time. Given advancements and intensification of diabetes management over the study period, we hypothesized there would be a decrease in DKA rates after the diagnosis of diabetes.

\section{Methods}

Data were extracted from the centralized population-based provincial administrative health databases that exist as part of a government funded universal health care system that provides coverage for medically necessary health care services for $\mathrm{BC}$ residents. The databases accessed via the infrastructure available through Population Data BC (www.popdatabc.ca) included physician fee-for-service claims for outpatient services (Medical Services Plan), client registration information, provincial prescription dispensations (PharmaNet), and health claims for hospital admissions (Discharge Abstract Database). ${ }^{17,18,19,20}$ Data were linked using an individual's personal health number, after which a validated diabetes case-finding definition was applied to identify all individuals with diabetes. ${ }^{21}$ Individuals were included in the diabetes database if they had any one of the following within a 1-year period: 1 hospital discharge code for diabetes (International Classification of Diseases [ICD], 9th edition, 250X or ICD10 E10X, E11X, E13X E14X); 2 outpatient physician claims coded as diabetes (ICD9 250X or ICD10 E10X, E11X, E13X, or $\mathrm{E} 14 \mathrm{X})$; $\geq 2$ prescription dispensations for insulin; $\geq 2$ prescription dispensations for an oral antidiabetic medication (except metformin); or any combination of 1 prescription dispensation for insulin, 1 prescription dispensation for an oral antidiabetic medicine, 2 prescriptions for metformin, and 1 outpatient physician claim coded as diabetes. Administrative health data from fiscal year 1995 (ie, April 1, 1995, to March 31, 1996) to fiscal year 2013 (ie, April 1, 2013, to March 31, 2014) were included in the Diabetes Database. For this study, we used data from fiscal year 2002 (ie, April 1, 2002, to March 31, 2003) to fiscal year 2012 (ie, April 1, 2012, to March 31, 2013).

\section{Study Population and Period}

This study was conducted in the province of BC, Canada. The centralized data used in this study cover all 5 regional health authorities across the province and includes patients seen 
in the province's single tertiary care pediatric center (British Columbia Children's Hospital), as well as those seen in regional and community-based pediatric diabetes clinics. During the study period, there were 5 pediatric endocrinologists providing diabetes care at British Columbia Children's Hospital and 3 pediatric endocrinologists practicing in regional clinics in the Fraser Health, Vancouver Coastal, and Vancouver Island health regions. In the Interior and Northern Health regions, community-based pediatric diabetes clinics were led by general pediatricians.

The date of diagnosis (index date) was defined as the date at which the individual first had a physician fee-for-service claim or hospital discharge diagnosis coded as diabetes. A novel validated algorithm was used to differentiate type 1 and type 2 diabetes in children and youth. ${ }^{22}$ Individuals were classified as having type 1 diabetes if they were $<10$ years old at the time of diabetes diagnosis, or $\geq 10$ years old at the time of diabetes diagnosis and had prescriptions dispensed for insulin and/or glucose monitoring strips only, with no prescription dispensations for oral hypoglycemic agents. Further refinement of the study population led to the following exclusions: cystic fibrosis related diabetes (ICD-9 277.0 or ICD-10 E84; $n=47$ ); suspected neonatal diabetes (index date $<6$ months of age; $n=5$ ); and nonpediatric cases (index date at $\geq 20$ years of age; $n=46$ ). An additional 83 patients were excluded owing to the lack of any diabetes-related ICD9/10 codes after the index date (potential false-positive cases) and another 29 patients with no in- or out-patient medical encounters after the index date suggesting the patient was either visiting $\mathrm{BC}$ or moved out of province at the time of or soon after the diabetes diagnosis.

Our cohort within the Diabetes Database dates back to 1995 and therefore, prevalent cases of diabetes diagnosed before 2002 fiscal year (April 1, 2002, to March 31, 2003) were included in our analysis of DKA after diagnosis of diabetes. Each individual diagnosed with type 1 diabetes at <20 years of age remained in the analyses regardless of their age in each fiscal year. The population at risk of DKA (ie, those with type 1 diabetes diagnosed at $<20$ years of age) were obtained from a recently published study reporting on incidence and prevalence trends of type 1 diabetes in BC using the same administrative dataset. ${ }^{2}$ 


\section{Main Outcomes: DKA at and after Diabetes Diagnosis}

Hospitalizations for DKA were identified using the ICD9 codes 250.1X (where $X=$ any integer) up until the 2001/2002 fiscal year, and ICD10 codes E101X thereafter. DKA at diagnosis of diabetes was defined as DKA hospitalizations that occurred $\leq 14$ days of the index date among all the incident cases of type 1 diabetes. Only 1 episode of DKA at the diagnosis of diabetes per individual was considered. DKA after the diagnosis of diabetes was defined as DKA hospitalizations occurring $>14$ days after the index date among all the prevalent cases of type 1 diabetes in that fiscal year. Individuals could have $>1$ hospitalization for DKA after the diagnosis of diabetes, but multiple hospitalization DKA codes within 7 days of each other were counted as 1 episode to prevent double counting in situations of hospital transfer or readmission. Episodes of DKA at and after the diagnosis of diabetes were counted for each fiscal year (April 1 to March 31) from 2002 to 2012.

\section{Statistical Analyses}

Incidence rate ratio (IRR) with corresponding 95\% Cls, and the temporal trend in the rate of DKA at and after the diagnosis of diabetes were estimated using Poisson regression models with robust standard error in Stata/SE statistical software version 14.2 program (StataCorp LO, College Station, Texas). Because number of events (as opposed to time to event) was our outcome of interest, we used (log of) the total number of people (as opposed to follow-up time) at risk as the offset term in the Poisson regression models. Incidence rates and the trend analyses were also conducted in a priori defined subgroups by age (0-4, 5-9, 10-14, and 15-19 years) and sex by introducing these variables in the regression models adjusting for the secular trend by fiscal year.

The denominator (at-risk population) for the incidence of DKA at and after the diagnosis of diabetes was the incident and prevalent cases of type 1 diabetes in the populations $<20$ years of age, respectively. Although our descriptive analysis of DKA after the diagnosis of diabetes events included individuals $\geq 20$ years of age, we limited our incidence rate calculation and trend analysis of DKA after the diagnosis of diabetes to those aged $<20$ years of age because our denominator of prevalent cases at risk for DKA was most accurate in this population based on previously published validation studies. ${ }^{21}$ In the 
sensitivity analysis, diabetes duration was further adjusted for in the regression models to examine its impact on the reported rates of DKA at and after the diagnosis of diabetes. Average annual percent change (APC) in the rates of DKA at and after the diagnosis of diabetes was examined using Joinpoint regression analysis program (V4.6.0.0; National Cancer Institute, Rockville, MD) with 4499 randomly permuted datasets that selected the best fitting piecewise continuous log-linear model at a significance level of $0.05 .^{23}$

\section{Results}

Overall, there were 1519 (mean age at first DKA, $12.6 \pm 5.9$ years; 50\% male) individuals in this study with $\geq 1$ DKA episode(s) during the study period (Table 1).

\section{DKA at Diagnosis of Diabetes}

Of the 2615 incident cases of type 1 diabetes that were identified between 2002 and 2012 (Table 2), 847 (32.4\%; 52\% male) were classified as having DKA at diagnosis of diabetes.

The mean age of DKA at diagnosis of diabetes was $9.9 \pm 4.8$ years. No sex differences (IRR, $1.03 ; 95 \% \mathrm{Cl}, 0.90-1.18 ; \mathrm{P}=.654$ ) were observed in the rates of DKA at diagnosis of diabetes over time (Figure 1, B).

Younger age at the time of diagnosis of type 1 diabetes was associated with a higher incidence of DKA at diagnosis of diabetes. Compared with those diagnosed with type 1 diabetes at 15-19 years old, children who were 0-4 years old at diagnosis had almost double (IRR, 1.99; 95\% Cl, 1.58, 2.49; $\mathrm{P}<.001$ ) the rate of DKA after adjusting for the trend by fiscal year. Similarly, compared with those diagnosed with type 1 diabetes at 1519 years of age, the IRR of DKA at diagnosis of diabetes for those diagnosed with type 1 diabetes at $5-9$ years and $10-14$ years was $1.22(95 \% \mathrm{Cl}, 0.98,1.51 ; \mathrm{P}=.072)$, and 1.35 $(95 \% \mathrm{Cl}, 1.10,1.66 ; \mathrm{P}=.004)$, respectively (Figure $1, \mathrm{C})$.

The rate of DKA at the time of diagnosis of diabetes ranged between 24.1 (2008) and 37.3 (2006) per 100 person-years (Figure 1, B). Poisson regression analyses showed an increasing trend of DKA at diagnosis of diabetes during 2002-2006 (IRR, 1.06; 95\% Cl, 0.99, 1.14; $\mathrm{P}=.095)$, a decreasing trend during 2006-2008 (IRR, 0.81;95\% Cl, 0.69, 0.95, $\mathrm{P}=.01)$, and an increasing trend during 2008-2012 (IRR, 1.06; 95\% Cl, 0.99, 1.14; $\mathrm{P}=.096)$. 
Joinpoint regression model showed similar trends as above; however, APC in DKA at diagnosis of diabetes over the study period was not statistically significant.

\section{DKA after the Diagnosis of Diabetes}

The total number of prevalent cases of diabetes increased from 1790 in 2002 to 2264 in 2012. Overall, 1886 hospitalizations for DKA after the diagnosis of diabetes were identified between 2002 and 2012. There were 507 (61\%) unique individuals with 1 DKA after the diagnosis of diabetes episode and 139 (17\%), 64 (8\%), 34 (4\%), and 92 (11\%) with 2, 3, 4, and $\geq 5$ episodes of DKA after the diagnosis of diabetes, respectively (Table 1 ). The median number of hospitalizations owing to DKA after the diagnosis of diabetes per individual was 1 (IQR, 1-2). The highest number of hospitalizations owing to DKA after the diagnosis of diabetes occurred between 3 and 8 years after diagnosis of type 1 diabetes, accounting for $58 \%$ of all events (Figure 2, A). The total number of hospitalizations owing to DKA after the diagnosis of diabetes increased over time, especially in those who were $\geq 20$ years of age at the time of DKA hospitalization (Figure 2, B). The mean age of individuals who had an episode of DKA after the diagnosis of diabetes increased from $16.0 \pm 4.0$ years in 2002 to $18.8 \pm 5.5$ years in 2012 (Table 3 ).

The rate of DKA after the diagnosis of diabetes in individuals $<20$ years of age ranged between 4.9 (2002) and 7.7 (2008) per 100 person-years, with females showing consistently higher rates than males (Figure 3, B). Poisson regression analyses provided an indication of an overall increase in the rate of DKA after the diagnosis of diabetes over the study period, but the evidence was not conclusive (IRR, 1.01; 95\% Cl, 0.99-1.03; P =.179). Although males showed an increase in the rate of DKA after the diagnosis of diabetes (IRR, 1.05; 95\% Cl, 1.02-1.08; $\mathrm{P}<.001)$, evidence of a decreasing rate in females was not conclusive (IRR, 0.99; 95\% Cl, 0.96-1.01; P =.173). However, even after adjusting for the increasing trend by fiscal year, females showed a $67 \%$ higher rate of incidence of DKA after the diagnosis of diabetes compared with their male counterparts (female vs male IRR, 1.67; 95\% Cl, 1.50-1.86; $\mathrm{P}<.001)$. 
As in the Poisson regression model, the Joinpoint regression model showed a higher APC of DKA after the diagnosis of diabetes in males (APC, 4.89\%; 95\% Cl, 0.56-9.41; $\mathrm{P}=.031$ ) compared with their female counterparts (APC, $-1.55 \% ; 95 \% \mathrm{Cl},-5.09$ to $2.12 ; \mathrm{P}=.359$ ).

The incidence of DKA after the diagnosis of diabetes showed an increasing trend with age at DKA episode. Adjusting for the temporal trend in fiscal year and duration of diabetes, the IRR was $1.03(95 \% \mathrm{Cl}, 0.67-1.58 ; \mathrm{P}=.910), 2.03(95 \% \mathrm{Cl}, 1.36-3.03 ; \mathrm{P}=.001)$, and 2.40 (95\% $\mathrm{Cl}, 1.61-3.58 ; \mathrm{P}<.001)$ in the $5-9,10-14$, and $15-19$ years groups, respectively, compared with the $0-4$ years group (Figure $3, \mathrm{C}$ ).

\section{Sensitivity Analysis}

In the sensitivity analysis, diabetes duration was not found to be a significant predictor of the reported rates of DKA at $(P=.528)$ and DKA after $(P=.282)$ the diagnosis of diabetes. Consequently, additional adjustment for diabetes duration in the regression models did not change the reported rates of DKA at or after the diagnosis of diabetes.

\section{Discussion}

Using population-based linked administrative health datasets, we found from 2002 to 2012 in BC, Canada, the incidence of DKA at diagnosis of type 1 diabetes remained stable yet occurred in more than one-third of newly diagnosed cases of diabetes, with a significantly higher rate in younger children (0-4 years of age). The incidence of DKA after the diagnosis of diabetes was stable in females, but significantly increased in male children and youth. Nonetheless, we found a $67 \%$ higher rate of DKA after the diagnosis of diabetes in females vs males as well as a higher rate of DKA after the diagnosis of diabetes in older children and youth compared with younger children. Our findings suggest that, despite multiple pharmaceutical and technological advancements to support the management of children and youth with type 1 diabetes, DKA both at and after the diagnosis of diabetes remains a significant health burden, with key demographic disparities.

DKA at diagnosis of type 1 diabetes in children and youth has remained unacceptably high over the 11-year period of our study. The incidence rates of DKA at diagnosis of type 1 diabetes in our study were similar to previous North American and European pediatric 
studies published between the 1990s to the early 2000s, as well as more recent US epidemiologic studies examining both adults and children with type 1 diabetes. ${ }^{10,11,14,15,24,25}$ The SEARCH for diabetes study in the US reported stable but high rates of DKA at diagnosis of diabetes of around 30\% from 2002 to 2010 in 5615 youth with type 1 diabetes. ${ }^{11}$ Similarly, the overall frequency of DKA at the time of diagnosis of diabetes in Austria remained stable at around 37\% over 20 years from 1989 to 2008, despite a significant increase in diabetes incidence. ${ }^{12}$ The Canadian province of Quebec, however, reported a relative increase of $2 \%$ per year of DKA at diagnosis of diabetes in youth (22\% in 2001 to 30\% in 2014), especially in younger children. ${ }^{16}$ The reasons for this difference in DKA trends at diagnosis of diabetes between BC and Quebec, both Canadian provinces with similar universal health care systems, are unclear and require further investigation.

DKA at diagnosis of type 1 diabetes is preventable if the signs and symptoms of diabetes are recognized early; however, efforts to decrease the incidence of DKA at diagnosis of diabetes by raising public awareness internationally has produced only mixed success. ${ }^{26,27}$ A recent systematic review of public interventions to increase type 1 diabetes awareness suggested that the use of posters, leaflets, diabetes educators, and the provision of capillary blood testing meters are common elements to successful DKA prevention interventions. ${ }^{28}$ Those who experience DKA at diagnosis of diabetes are at increased risk of mortality than those who did not have DKA at diagnosis of diabetes. ${ }^{29}$ Furthermore, emerging data suggest that DKA at diagnosis of diabetes in those $<10$ years of age is associated with detrimental long-term neurocognitive changes and altered brain growth, a potentially irreversible consequence. ${ }^{5}$ DKA at diagnosis of diabetes is also associated with worsening glycemic control over time, compared with those who were not in DKA at diabetes diagnosis, independent of demographic, socioeconomic, treatment-related factors, and beta-cell reserve. ${ }^{30}$ Further research and development of cost-effective strategies to prevent DKA at diagnosis of type 1 diabetes, such as populationbased islet cell autoantibody screening for early detection, and patient-level studies in those most likely to experience DKA at diabetes diagnosis (ie, the $<5$ year old age group), should be explored. ${ }^{31,32}$ 
The rate of DKA after the diagnosis of type 1 diabetes in BC showed an increasing trend until 2008 followed by a decrease with no evidence of an increase from 2002 to 2012, which is consistent with our previously published prevalence trends of type 1 diabetes in BC over the same time period. ${ }^{2}$ However, a higher incidence of DKA after the diagnosis of type 1 diabetes in female children and youth reveals a significant disparity in health care in pediatric diabetes, and has also been reported in other pediatric studies. ${ }^{33,34}$ In contrast, higher rates of DKA have been observed in adult males with type 1 diabetes, as well as an increasing trend in DKA rates over time. For example, Desai et al found that the total number of DKA hospitalizations in all age groups in the US increased by 59\% from 2003 to 2014, and the frequency of DKA hospital discharges remained higher in males vs females over their study period. ${ }^{15}$ Similarly, Benoit et al reported an increase in DKA hospitalizations in all age groups from 19.5 to 30.2 per 1000 persons with diabetes from 2009 to 2014, with higher DKA rates in males compared with females. ${ }^{14}$ Similar to our study, Zhong et al found a substantial increase in annual incidence of DKA hospitalizations by $14.1 \%$ in adults with type 1 diabetes from 2004 to 2007 in the UK, with rates remaining stably high thereafter; however, DKA was again found to be more common in males than females. ${ }^{35}$ These studies had several limitations. They did not describe children and adults separately and did not differentiate between type 1 and type 2 diabetes (except Zhong et al) or describe DKA episodes at and after diagnosis of diabetes separately. In contrast, a German study did describe self-reported incidence rates of DKA-related hospitalizations after diagnosis as being stable at around 10 events per 100 person-years in 2009/2010, 2012/2013, and $2015 / 2016$. They also reported that a longer duration of diabetes was associated with a decreased rate of hospitalization for DKA after the diagnosis of diabetes. ${ }^{34}$ However, this retrospective cross-sectional survey was limited by under-reporting, recall bias, and selection bias. Differences in health systems, models of care (ie, transition clinics), and supporting resources (ie, diabetes educators, mental health specialists) may also explain these disparate findings between Germany and Canada.

We found that DKA after the diagnosis of type 1 diabetes occurred more frequently in those $\geq 10$ years of age. The heightened risk of DKA in older children and adolescents is well-documented and multifactorial, including poor glycemic control, psychological 
comorbidities, eating disorders, fear of hypoglycemia, and increasing alcohol and recreational drug use. ${ }^{36,37,38}$ Furthermore, in emerging and young adults with type 1 diabetes, abrupt changes in health care setting and delivery during the transition process combined with the need for autonomy, and potential for risk-taking behaviors are associated with disengagement from regular care, deterioration in glycemic control, and risk of DKA. ${ }^{39}$ Successful engagement with a multidisciplinary transition service has been shown to prevent the deterioration in hemoglobin A1C after transition, as well as decrease DKA-related hospitalizations. ${ }^{40}$ More research is needed to better understand whether transition interventions will help to reverse the increasing trends of DKA after the diagnosis of type 1 diabetes in older youth and young adults.

Our study demonstrated that more than one-half of the DKA episodes after the diagnosis of diabetes occurred between 3 and 8 years after a type 1 diabetes diagnosis. Given that the mean age of diabetes diagnosis is around 10 years of age, this timing coincides with the end of the honeymoon period, as well as the increasing independence and insulin resistance typical of adolescence. Nevertheless, DKA after the diagnosis of diabetes is preventable. Poor adherence to diabetes care has been shown to be associated with higher rates of DKA after the diagnosis of diabetes. ${ }^{41}$ In BC, we previously reported a $78 \%$ reduction in the odds of adhering to national and international diabetes guidelines at 4 years post-diagnosis of type 1 diabetes in youth. ${ }^{42,43,44,45}$ Further, although a reduction in adherence to clinical practice guidelines (ie, frequency of diabetes-related physician visits, hemoglobin A1C tests, and screening for diabetes-related complications) was observed across all age groups with increasing years from diabetes diagnosis, poorest adherence was observed in those aged $15-19$ and 20-24 years. ${ }^{45}$ Similarly, Hilliard et al demonstrated that a longer duration of diabetes predicted poorer diabetes control and management, in addition to ethnic minority status, unmarried caregiver status, and greater psychosocial distress. ${ }^{46}$ Therefore, nonadherence may be contributing to the high rates of DKA after diabetes diagnosis that was observed with increased duration of diabetes and in the $\geq 15$-year age group in our current study. 
A lack of key demographic (ie, socioeconomic status, education level) and clinical (ie, insulin regimen/doses, continuous glucose monitoring system use) data within administrative health data made the assessment of causal factors beyond the scope of this study. It is possible that other factors, such as patient location (rural vs urban) and access to an endocrinologist contributed to the increasing trends of DKA after the diagnosis of diabetes. ${ }^{47,48}$ However, over the 11-year study period, the number of pediatric endocrinologists practicing in $\mathrm{BC}$ increased from 5 to 8 and more outreach clinics were implemented across the province. Insulin pumps became commercially available in BC in the early 2000s and became government funded in 2008. The increase in DKA episodes after the diagnosis of type 1 diabetes in males caused by pump failure may have contributed to this trend and should be further examined. ${ }^{49}$

This study has several limitations that accompany the use of health administrative data. Because diagnostic coding is performed by physicians and subsequently verified by hospitals and institutions, DKA episodes may have been missed, or inadvertently included, owing to incorrect coding. However, all medical services are centrally reported for the purpose of physician billing in Canada's single-payer health care system, minimizing the risk of missing data. Our dataset did not include Aboriginal children and youth living on reserve; however, rates of type 1 diabetes are relatively low in this population. We also did not examine the mortality rates in this study because mortality rates are low in this population and we analyzed the data by each fiscal year (rather than calendar year), thereby ensuring that all data that contributed to the study period were included. Administrative data are limited in their breadth and thus, are not helpful in delineating patient, provider and health system factors that might contribute to DKA at and after the diagnosis of diabetes. For this study, data were available only to 2012 because administrative health data are housed centrally in the province, making access to data a lengthy process. As a result, we may have not captured the impact of more recent advancements such as continuous glucose monitoring system. However, our study period is similar to that of recently published studies, allowing for meaningful comparisons. ${ }^{14,15,16,35}$ This study also has several strengths. The study spans $>11$ years of follow-up time. We used a unified populationbased linked administrative health database from a single-payer health care system to 
comprehensively capture most, if not all, children at risk, avoiding the risk of nonresponse bias. Unlike other studies using administrative data, the use of a novel validated algorithm that differentiates childhood type 1 and type 2 diabetes allowed us to describe DKA in type 1 diabetes specifically. ${ }^{15,16,22}$ Although we were not able to separate those with insulintreated monogenic diabetes from the type 1 group, these patients are rare and therefore should not have significantly affected our results. By separating episodes of DKA into DKA at and after the diagnosis of type 1 diabetes, we were able to analyze key demographic contributors to increasing rates of DKA. We excluded DKA admissions within 7 days of a previous DKA discharge to identify distinct episodes of DKA after the diagnosis of diabetes and avoid double counting failed hospital discharges or transfer between hospitals.

Over our study period, DKA after the diagnosis of diabetes increased at a rate of almost $5 \%$ per year in males, but not in females. These findings represent potential gaps in health care services. DKA, whether at or after the diagnosis of diabetes, contributes to significant acute and long-term complications. Patient-oriented research is needed to explore why rates of DKA after the diagnosis of type 1 diabetes are increasing in males, yet higher overall in females. Also, research is needed to understand why those diagnosed at a young age and those transitioning from pediatric to adult health care are at higher risk of DKA. 


\section{References}

[1] International Diabetes Federation. IDF Diabetes Atlas. Brussels, Belgium: International Diabetes Federation; 2017.

[2] Fox DA, Islam N, Sutherland J, Reimer K, Amed S. Type 1 diabetes incidence and prevalence trends in a cohort of Canadian children and youth. Pediatr Diabetes. 2018;19:501-5.

[3] Kaufman FR, Halvorson M. The treatment and prevention of diabetic ketoacidosis in children and adolescents with type I diabetes mellitus. Pediatr Ann. 1999;28:576-82.

[4] Hursh BE, Ronsley R, Islam N, Mammen C, Panagiotopoulos C. Acute Kidney Injury in Children With Type 1 Diabetes Hospitalized for Diabetic Ketoacidosis. JAMA pediatrics. 2017;171:e170020.

[5] Aye T, Mazaika PK, Mauras N, Marzelli MJ, Shen H, Hershey T, et al. Impact of Early Diabetic Ketoacidosis on the Developing Brain. Diabetes Care. 2019;42:443-9.

[6] Grosse J, Hornstein H, Manuwald U, Kugler J, Glauche I, Rothe U. Incidence of Diabetic Ketoacidosis of New-Onset Type 1 Diabetes in Children and Adolescents in Different Countries Correlates with Human Development Index (HDI): An Updated Systematic Review, Meta-Analysis, and Meta-Regression. Horm Metab Res. 2018;50:209-22. [7] Wolfsdorf JI, Glaser N, Agus M, Fritsch M, Hanas R, Rewers A, et al. ISPAD Clinical Practice Consensus Guidelines 2018: Diabetic ketoacidosis and the hyperglycemic hyperosmolar state. Pediatr Diabetes. 2018;19 Suppl 27:155-77.

[8] Diabetes Control and Complications Trial Research Group, Nathan DM, Genuth S, Lachin J, Cleary P, Crofford O, et al. The effect of intensive treatment of diabetes on the 
development and progression of long-term complications in insulin-dependent diabetes mellitus. N Engl J Med. 1993;329:977-86.

[9] Alaghehbandan R, Collins KD, Newhook LA, MacDonald D. Childhood type 1 diabetes mellitus in Newfoundland and Labrador, Canada. Diabetes Res Clin Pract. 2006;74:82-9. [10] Curtis JR, To T, Muirhead S, Cummings E, Daneman D. Recent trends in hospitalization for diabetic ketoacidosis in ontario children. Diabetes Care. 2002;25:1591-6.

[11] Dabelea D, Rewers A, Stafford JM, Standiford DA, Lawrence JM, Saydah S, et al. Trends in the prevalence of ketoacidosis at diabetes diagnosis: the SEARCH for diabetes in youth study. Pediatrics. 2014;133:e938-45.

[12] Schober E, Rami B, Waldhoer T, Austrian Diabetes Incidence Study G. Diabetic ketoacidosis at diagnosis in Austrian children in 1989-2008: a population-based analysis. Diabetologia. 2010;53:1057-61.

[13] Bui TP, Werther GA, Cameron FJ. Trends in diabetic ketoacidosis in childhood and adolescence: a 15-yr experience. Pediatr Diabetes. 2002;3:82-8.

[14] Benoit SR, Zhang Y, Geiss LS, Gregg EW, Albright A. Trends in Diabetic Ketoacidosis Hospitalizations and In-Hospital Mortality - United States, 2000-2014. MMWR Morb Mortal Wkly Rep. 2018;67:362-5.

[15] Desai D, Mehta D, Mathias P, Menon G, Schubart UK. Health Care Utilization and Burden of Diabetic Ketoacidosis in the U.S. Over the Past Decade: A Nationwide Analysis. Diabetes Care. 2018;41:1631-8.

[16] Robinson ME, Li P, Rahme E, Simard M, Larocque I, Nakhla MM. Increasing prevalence of diabetic ketoacidosis at diabetes diagnosis among children in Quebec: a populationbased retrospective cohort study. CMAJ Open. 2019;7:E300-E5. 
[17] British Columbia Ministry of Health. Medical Services Plan (MSP). Payment Information File. Population Data BC. Data Extract. MOH (2017). http://www.popdata.bc.ca/data. [18] British Columbia Ministry of Health (2017): Consolidation File (MSP Registration \& Premium Billing). Population Data BC. Data Extract. MOH (2017).

\section{http://www.popdata.bc.ca/data.}

[19] British Columbia Ministry of Health (2017): PharmaNet. BC Ministry of Health. Data Extract. Data Stewardship Committee (2017). http://www.popdata.bc.ca/data.

[20] Canadian Institute for Health Information (2017): Discharge Abstract Database (Hospital Separations). Population Data BC. Data Extract. MOH (2017).

\section{http://www.popdata.bc.ca/data.}

[21] Amed S, Vanderloo SE, Metzger D, Collet JP, Reimer K, McCrea P, et al. Validation of diabetes case definitions using administrative claims data. Diabet Med. 2011;28:424-7. [22] Vanderloo SE, Johnson JA, Reimer K, McCrea P, Nuernberger K, Krueger H, et al. Validation of classification algorithms for childhood diabetes identified from administrative data. Pediatr Diabetes. 2012;13:229-34.

[23] Kim HJ, Fay MP, Feuer EJ, Midthune DN. Permutation tests for joinpoint regression with applications to cancer rates. Stat Med. 2000;19:335-51.

[24] Maniatis AK, Goehrig SH, Gao D, Rewers A, Walravens P, Klingensmith GJ. Increased incidence and severity of diabetic ketoacidosis among uninsured children with newly diagnosed type 1 diabetes mellitus. Pediatr Diabetes. 2005;6:79-83.

[25] Levy-Marchal C, Patterson CC, Green A, Europe EASG, Diabetes. Geographical variation of presentation at diagnosis of type I diabetes in children: the EURODIAB study. European and Dibetes. Diabetologia. 2001;44 Suppl 3:B75-80. 
[26] King BR, Howard NJ, Verge CF, Jack MM, Govind N, Jameson K, et al. A diabetes awareness campaign prevents diabetic ketoacidosis in children at their initial presentation with type 1 diabetes. Pediatr Diabetes. 2012;13:647-51.

[27] Vanelli M, Chiari G, Ghizzoni L, Costi G, Giacalone T, Chiarelli F. Effectiveness of a prevention program for diabetic ketoacidosis in children. An 8-year study in schools and private practices. Diabetes Care. 1999;22:7-9.

[28] Deylami R, Townson J, Mann M, Gregory JW. Systematic review of publicity interventions to increase awareness amongst healthcare professionals and the public to promote earlier diagnosis of type 1 diabetes in children and young people. Pediatr Diabetes. 2018;19:566-73.

[29] Fredheim S, Johannesen J, Johansen A, Lyngsoe L, Rida H, Andersen ML, et al. Diabetic ketoacidosis at the onset of type 1 diabetes is associated with future $\mathrm{HbA1c}$ levels. Diabetologia. 2013;56:995-1003. [30] Duca LM, Reboussin BA, Pihoker C, Imperatore G, Saydah S, Mayer-Davis E, et al. Diabetic ketoacidosis at diagnosis of type 1 diabetes and glycemic control over time: The SEARCH for diabetes in youth study. Pediatr Diabetes. 2019;20:172-9.

[31] Insel RA, Dunne JL, Ziegler AG. General population screening for type 1 diabetes: has its time come? Curr Opin Endocrinol Diabetes Obes. 2015;22:270-6.

[32] Raab J, Haupt F, Scholz M, Matzke C, Warncke K, Lange K, et al. Capillary blood islet autoantibody screening for identifying pre-type 1 diabetes in the general population: design and initial results of the Fr1da study. BMJ Open. 2016;6:e011144. 
[33] Fritsch M, Rosenbauer J, Schober E, Neu A, Placzek K, Holl RW, et al. Predictors of diabetic ketoacidosis in children and adolescents with type 1 diabetes. Experience from a large multicentre database. Pediatr Diabetes. 2011;12:307-12.

[34] Karges B, Rosenbauer J, Holterhus PM, Beyer P, Seithe H, Vogel C, et al. Hospital admission for diabetic ketoacidosis or severe hypoglycemia in 31,330 young patients with type 1 diabetes. Eur J Endocrinol. 2015;173:341-50.

[35] Zhong VW, Juhaeri J, Mayer-Davis EJ. Trends in Hospital Admission for Diabetic Ketoacidosis in Adults With Type 1 and Type 2 Diabetes in England, 1998-2013: A Retrospective Cohort Study. Diabetes Care. 2018;41:1870-7.

[36] Isidro ML, Jorge S. Recreational drug abuse in patients hospitalized for diabetic ketosis or diabetic ketoacidosis. Acta Diabetol. 2013;50:183-7.

[37] Polonsky WH, Anderson BJ, Lohrer PA, Aponte JE, Jacobson AM, Cole CF. Insulin omission in women with IDDM. Diabetes Care. 1994;17:1178-85.

[38] Cengiz E, Xing D, Wong JC, Wolfsdorf JI, Haymond MW, Rewers A, et al. Severe hypoglycemia and diabetic ketoacidosis among youth with type 1 diabetes in the T1D Exchange clinic registry. Pediatr Diabetes. 2013;14:447-54.

[39] Kapellen TM, Muther S, Schwandt A, Grulich-Henn J, Schenk B, Schwab KO, et al. Transition to adult diabetes care in Germany-High risk for acute complications and declining metabolic control during the transition phase. Pediatr Diabetes. 2018;19:1094-9. [40] Farrell K, Fernandez R, Salamonson Y, Griffiths R, Holmes-Walker DJ. Health outcomes for youth with type 1 diabetes at 18 months and 30 months post transition from pediatric to adult care. Diabetes Res Clin Pract. 2018;139:163-9. 
[41] Jacobson AM, Hauser ST, Willett J, Wolfsdorf JI, Herman L. Consequences of irregular versus continuous medical follow-up in children and adolescents with insulin-dependent diabetes mellitus. J Pediatr. 1997;131:727-33.

[42] Canadian Diabetes Association Clinical Practice Guidelines Expert C, Cheng AY. Canadian Diabetes Association 2013 clinical practice guidelines for the prevention and management of diabetes in Canada. Introduction. Can J Diabetes. 2013;37 Suppl 1:S1-3.

[43] American Diabetes Association. Standards of medical care in diabetes--2012. Diabetes Care. 2012;35 Suppl 1:S11-63.

[44] Rewers M, Pihoker C, Donaghue K, Hanas R, Swift P, Klingensmith GJ. Assessment and monitoring of glycemic control in children and adolescents with diabetes. Pediatr Diabetes. 2009;10 Suppl 12:71-81.

[45] Amed S, Nuernberger K, McCrea P, Reimer K, Krueger H, Aydede SK, et al. Adherence to clinical practice guidelines in the management of children, youth, and young adults with type 1 diabetes--a prospective population cohort study. J Pediatr. 2013;163:543-8. [46] Hilliard ME, Wu YP, Rausch J, Dolan LM, Hood KK. Predictors of deteriorations in diabetes management and control in adolescents with type 1 diabetes. The Journal of adolescent health : official publication of the Society for Adolescent Medicine. 2013;52:2834.

[47] Fox DA, Islam N, Amed S. Type 1 diabetes outcomes: Does distance to clinic matter? Pediatr Diabetes. 2018;19:1331-6.

[48] Nakhla M, Rahme E, Simard M, Larocque I, Legault L, Li P. Risk of ketoacidosis in children at the time of diabetes mellitus diagnosis by primary caregiver status: a population-based retrospective cohort study. CMAJ. 2018;190:E416-E21. 
[49] Hanas R, Lindgren F, Lindblad B. A 2-yr national population study of pediatric ketoacidosis in Sweden: predisposing conditions and insulin pump use. Pediatr Diabetes. 2009;10:33-7. 


\title{
Figure Legends
}

Figure 1. A. Number of incident cases of DKA at diagnosis of type 1 diabetes; B. incidence of DKA at diagnosis of type 1 diabetes by sex and C. by age

\begin{abstract}
Figure 2. A. Number of episodes of DKA after diagnosis of type 1 diabetes by duration of diabetes in British Columbia (2002-2012). B. Total number of episodes of DKA after diagnosis of type 1 diabetes for all age-at-DKA episode groups by fiscal year, stratified by age-at-DKA episode groups. C. Number of episodes of DKA after diagnosis of type 1 diabetes by age-at-DKA groups.
\end{abstract}

Figure 3. Number of prevalent cases of type 1 diabetes and number of episodes of DKA after diagnosis of type 1 diabetes in British Columbia, Canada; B. Incidence of DKA after diagnosis of type 1 diabetes by sex; and C. by age-at-DKA episode.

\section{Table Legend}

Table 1. Demographic characteristics of the study population

\section{Appendix Legend}

Table 2; online only. Demographic characteristics of children with DKA at diagnosis of type 1 diabetes in British Columbia (2002-2012)

Table 3; online only. Demographic characteristics of children with DKA after the diagnosis of type 1 diabetes in British Columbia (2002-2012) 
Table 1. Demographic characteristics of the study population

\begin{tabular}{|c|c|}
\hline \multicolumn{2}{|c|}{ All children with at least one DKA-related visit } \\
\hline Individuals; $\mathrm{n}$ & 1519 \\
\hline Male; n (\%) & $756(50 \%)$ \\
\hline Mean age at DKA episode; years (SD) & $12.6(5.9)$ \\
\hline Minimum age & 0.6 \\
\hline Maximum age & 33 \\
\hline \multicolumn{2}{|l|}{ DKA at diagnosis of type 1 diabetes } \\
\hline Individuals; $\mathrm{n}$ & 847 \\
\hline Male; n (\%) & $440(52 \%)$ \\
\hline \multicolumn{2}{|l|}{ Age at DKA episode; years } \\
\hline Mean (SD) & $9.9(4.8)$ \\
\hline $0-4$ years $(n)$ & 176 \\
\hline $5-9$ years $(n)$ & 234 \\
\hline $10-14$ years $(n)$ & 306 \\
\hline $15-19$ years $(n)$ & 131 \\
\hline \multicolumn{2}{|c|}{ DKA after the diagnosis of type 1 diabetes } \\
\hline Unique individuals; $\mathrm{n}$ & 836 \\
\hline Male; n (\%) & $390(47 \%)$ \\
\hline \multicolumn{2}{|l|}{ Age at first DKA episode; years } \\
\hline Mean (SD) & $15.7(5.2)$ \\
\hline \multicolumn{2}{|l|}{ DKA episodes per individual ( $n$ ) } \\
\hline Median (IQR) & $1(1-2)$ \\
\hline 1 episode; n (\%) & $507(61 \%)$ \\
\hline 2 episodes; $n(\%)$ & $139(17 \%)$ \\
\hline 3 episodes; $n$ (\%) & $64(8 \%)$ \\
\hline 4 episodes; $n(\%)$ & $34(4 \%)$ \\
\hline$\geq 5$ episodes; $n(\%)$ & $92(11 \%)$ \\
\hline
\end{tabular}

DKA: Diabetic ketoacidosis; SD: Standard deviation; IQR: interquartile range 
Table 2; online only. Demographic characteristics of children with DKA at diagnosis of type 1 diabetes in British Columbia (2002-2012)

\begin{tabular}{|c|c|c|c|c|c|c|c|c|c|}
\hline \multirow{2}{*}{ Fiscal year } & \multirow{2}{*}{ Incident cases } & \multirow{2}{*}{$\begin{array}{l}\text { Mean age of incident cases } \\
\text { (SD) }\end{array}$} & \multirow{2}{*}{$N$} & \multirow{2}{*}{ Female } & \multirow{2}{*}{ Male } & \multicolumn{4}{|c|}{ Age (years) at diabetes diagnosis } \\
\hline & & & & & & $0-4.9$ & $5-9.9$ & $10-14.9$ & $15-19.9$ \\
\hline 2002 & 225 & $10.53(4.87)$ & 59 & 24 & 35 & 11 & 18 & 20 & 10 \\
\hline 2003 & 244 & $10.27(4.59)$ & 86 & 38 & 48 & 15 & 29 & 31 & 11 \\
\hline 2004 & 248 & $10.39(4.77)$ & 83 & 41 & 42 & 18 & 16 & 33 & 16 \\
\hline 2005 & 201 & $10.00(5.14)$ & 67 & 31 & 36 & 15 & 22 & 21 & 9 \\
\hline 2006 & 233 & $10.41(4.67)$ & 87 & 43 & 44 & 18 & 29 & 27 & 13 \\
\hline 2007 & 250 & $10.44(4.49)$ & 85 & 40 & 45 & 16 & 27 & 29 & 13 \\
\hline 2008 & 241 & 9.86 (4.95) & 58 & 25 & 33 & 17 & 13 & 20 & 8 \\
\hline 2009 & 229 & $10.16(4.70)$ & 73 & 32 & 41 & 10 & 15 & 34 & 14 \\
\hline 2010 & 248 & $10.23(4.92)$ & 86 & 53 & 33 & 21 & 29 & 26 & 10 \\
\hline 2011 & 249 & $9.72(5.00)$ & 81 & 42 & 39 & 24 & 19 & 29 & 9 \\
\hline 2012 & 247 & $10.2(4.66)$ & 82 & 34 & 48 & 11 & 17 & 36 & 18 \\
\hline
\end{tabular}

DKA: Diabetic ketoacidosis; SD: Standard deviation

|| Accepted Version || J Pediatr. 2020;221:165-173.e2 || https://doi.org/10.1016/j.jpeds.2020.02.069 
Table 3; Online Only. Demographic characteristics of children with DKA after the diagnosis of type 1 diabetes in British Columbia (20022012)

\begin{tabular}{|c|c|c|c|c|c|c|c|c|c|c|c|c|}
\hline \multirow{2}{*}{$\begin{array}{l}\text { Fiscal } \\
\text { year }\end{array}$} & \multirow{2}{*}{$\begin{array}{l}\text { Prevalent } \\
\text { cases }(n)\end{array}$} & \multirow{2}{*}{$\begin{array}{l}\text { Mean age (years) } \\
\text { of prevalent } \\
\text { cases (SD) }\end{array}$} & \multirow{2}{*}{$\begin{array}{l}\text { Individuals with } \geq 1 \\
\text { episode of DKA after } \\
\text { the diagnosis of type } \\
1 \text { diabetes }(n)\end{array}$} & \multirow{2}{*}{$\begin{array}{l}\text { Episodes of } \\
\text { DKA after } \\
\text { the } \\
\text { diagnosis of } \\
\text { type } 1 \\
\text { diabetes }(n)\end{array}$} & \multirow{2}{*}{$\begin{array}{l}\text { Mean age } \\
\text { (years) at } \\
\text { DKA } \\
\text { episode } \\
\text { (SD) }\end{array}$} & \multirow{2}{*}{$\begin{array}{l}\text { Mean } \\
\text { duration of } \\
\text { diabetes } \\
\text { (years) }\end{array}$} & \multirow{2}{*}{$\begin{array}{l}\text { Female } \\
\text { (n) }\end{array}$} & \multirow{2}{*}{$\begin{array}{l}\text { Male } \\
\text { (n) }\end{array}$} & \multicolumn{4}{|c|}{ Age (years) at diabetes diagnosis } \\
\hline & & & & & & & & & $0-4.9$ & $5-9.9$ & $10-14.9$ & $15-19.9$ \\
\hline 2002 & 1790 & $12.87(5.02)$ & 61 & 94 & $16.0(4.0)$ & 4.4 & 55 & 39 & 7 & 15 & 59 & 13 \\
\hline 2003 & 1858 & $12.83(4.85)$ & 89 & 138 & $15.8(3.8)$ & 4.6 & 89 & 49 & 5 & 40 & 73 & 20 \\
\hline 2004 & 1910 & $12.90(4.76)$ & 90 & 127 & $15.9(4.2)$ & 5.0 & 88 & 39 & 10 & 31 & 71 & 15 \\
\hline 2005 & 1934 & $12.91(4.70)$ & 109 & 150 & $16.6(4.0)$ & 5.5 & 85 & 65 & 11 & 48 & 66 & 25 \\
\hline 2006 & 1961 & $12.91(4.60)$ & 113 & 145 & $16.7(4.5)$ & 5.8 & 82 & 63 & 19 & 43 & 55 & 28 \\
\hline 2007 & 2037 & $12.99(4.49)$ & 145 & 187 & $16.7(4.9)$ & 6.0 & 99 & 88 & 22 & 53 & 84 & 28 \\
\hline 2008 & 2110 & $13.02(4.43)$ & 159 & 202 & $16.7(5.0)$ & 6.4 & 115 & 87 & 38 & 57 & 72 & 35 \\
\hline 2009 & 2126 & $13.07(4.34)$ & 150 & 188 & $17.5(5.4)$ & 6.8 & 107 & 81 & 26 & 48 & 77 & 37 \\
\hline 2010 & 2193 & $13.15(4.31)$ & 166 & 222 & $18.3(5.8)$ & 8.0 & 122 & 100 & 35 & 61 & 86 & 40 \\
\hline 2011 & 2237 & $13.16(4.26)$ & 167 & 217 & $18.2(5.4)$ & 7.7 & 121 & 96 & 37 & 64 & 69 & 47 \\
\hline 2012 & 2264 & $13.17(4.25)$ & 170 & 216 & $18.8(5.5)$ & 8.7 & 101 & 115 & 33 & 80 & 63 & 40 \\
\hline
\end{tabular}

DKA: Diabetic ketoacidosis; SD: Standard deviation

|| Accepted Version || J Pediatr. 2020;221:165-173.e2 || https://doi.org/10.1016/j.jpeds.2020.02.069 
Figure 1. A. Number of incident cases of DKA at diagnosis of type 1 diabetes; B. incidence of DKA at diagnosis of type 1 diabetes by sex and C. by age.

A.

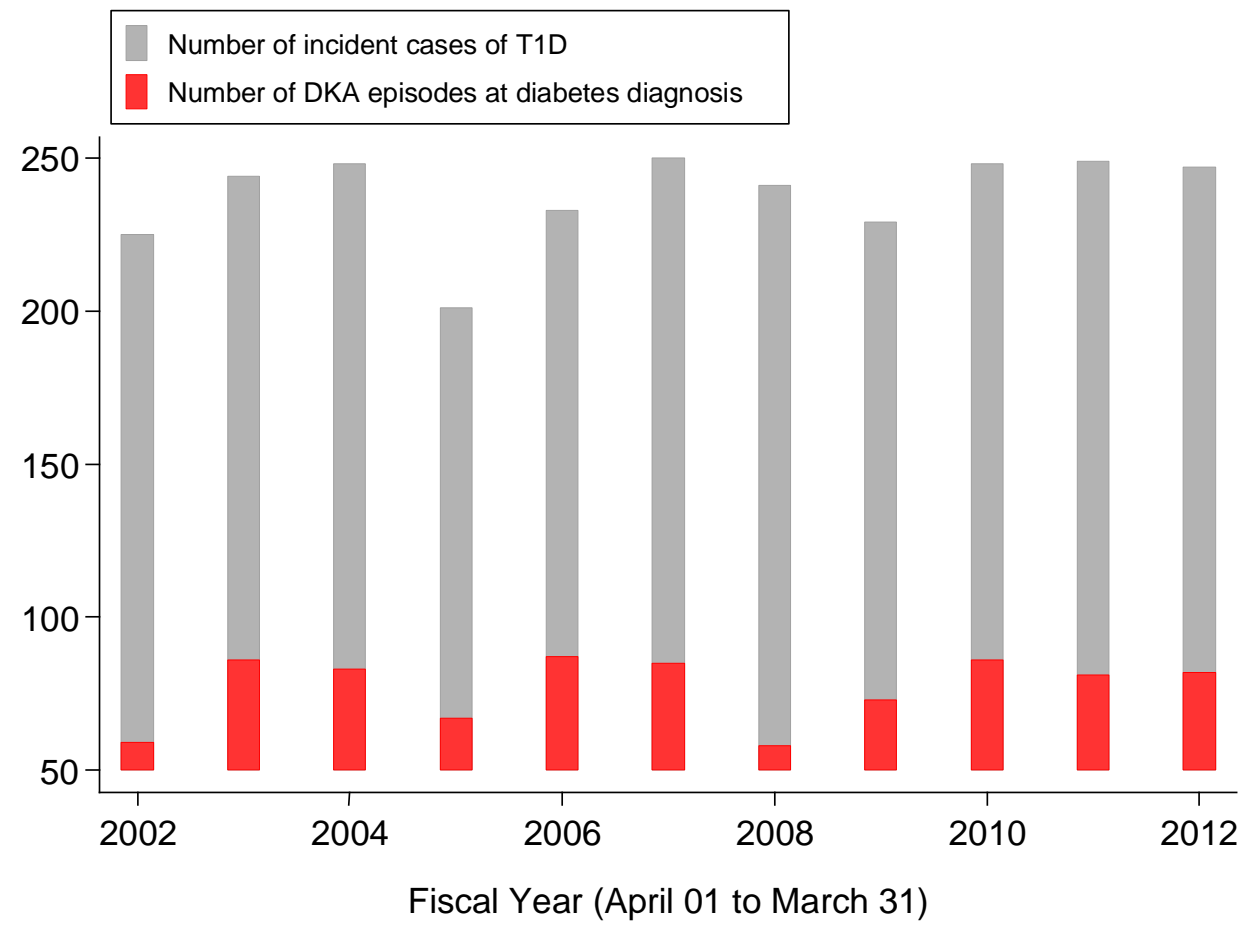


B.

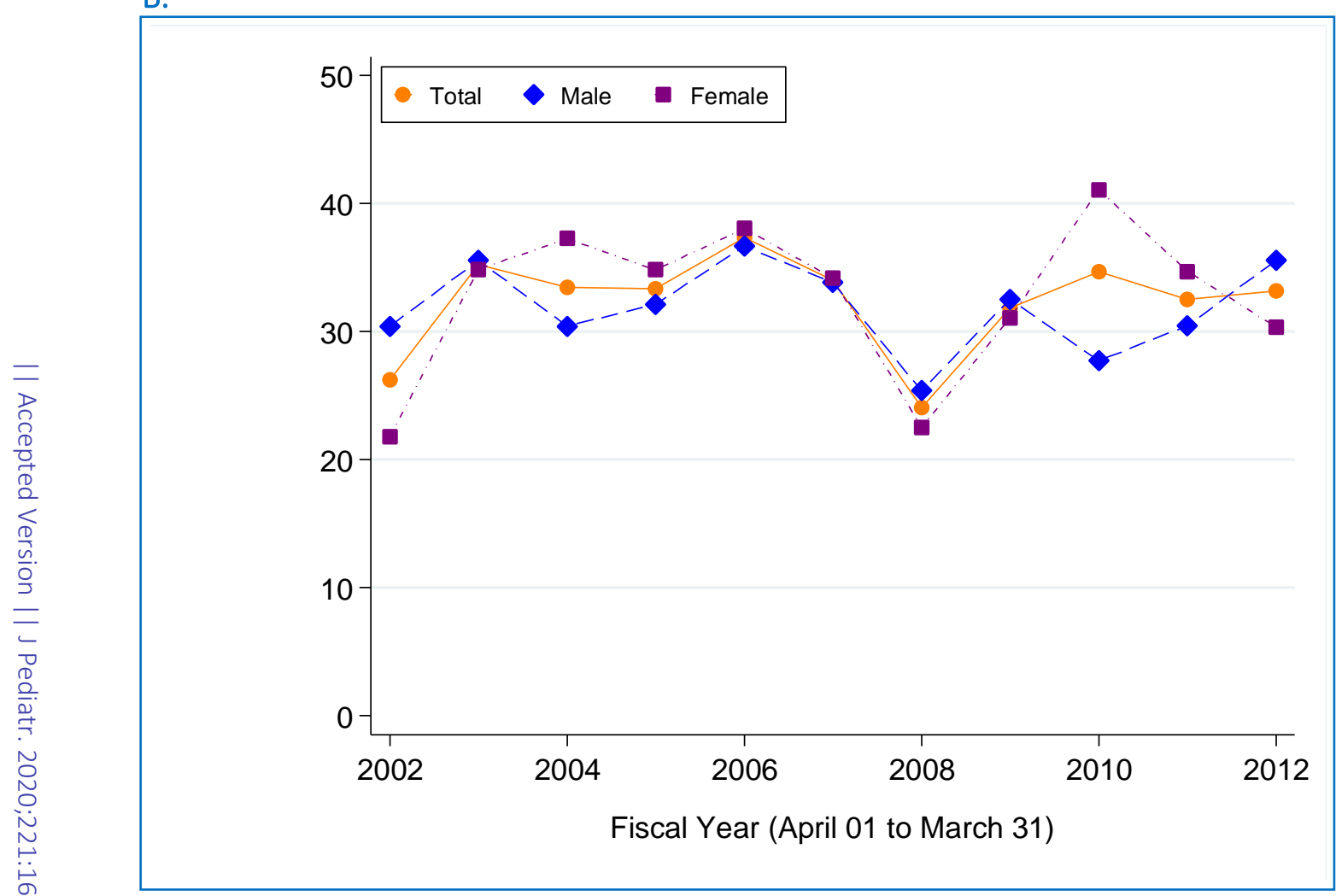

c.

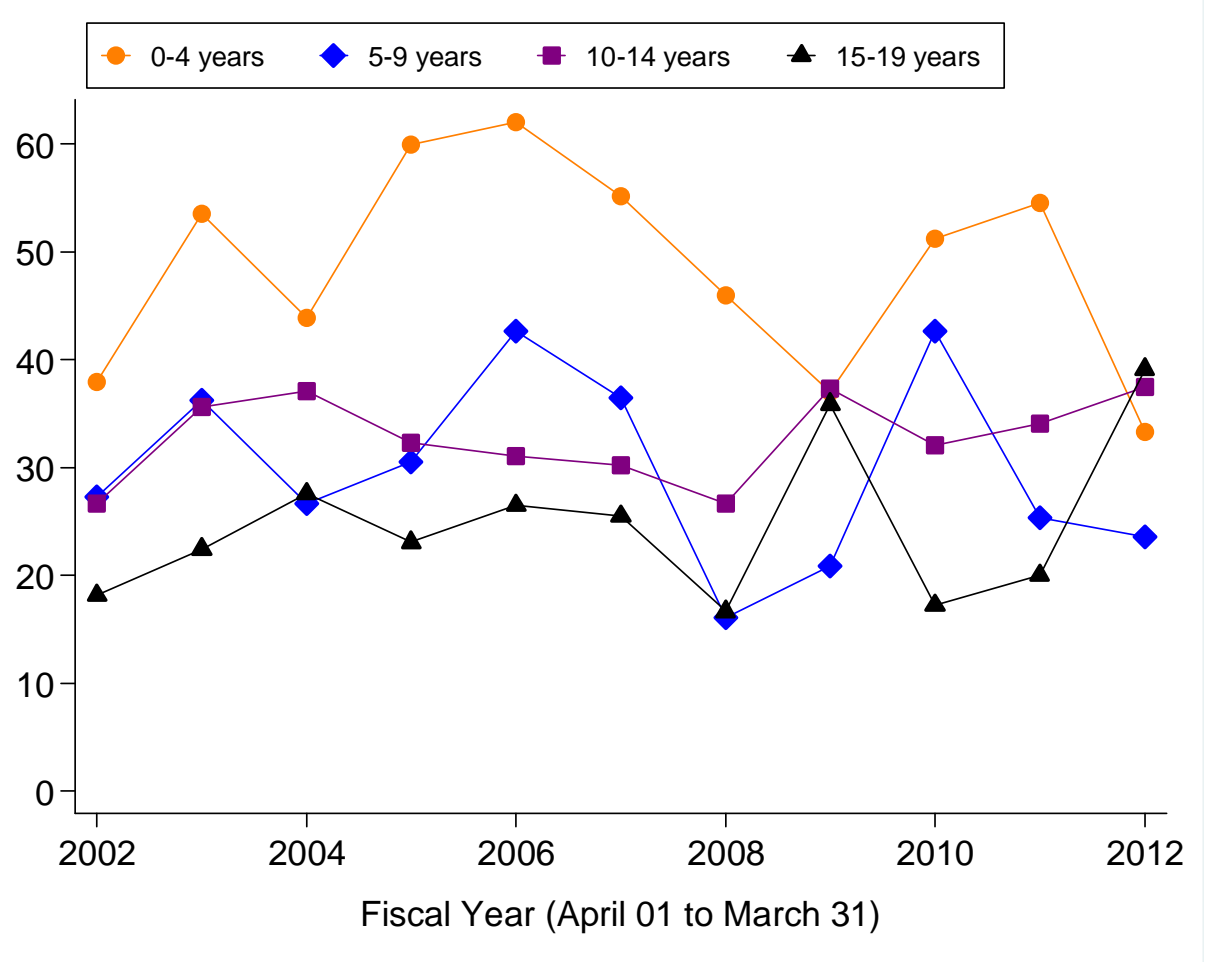


Figure 2. A. Number of episodes of DKA after the diagnosis of type 1 diabetes by duration of diabetes in British Columbia (2002-2012). B. Total number of episodes of DKA after the diagnosis of type 1 diabetes for all age-at-DKA episode groups by fiscal year, stratified by age-at-DKA episode groups. C. Number of episodes of DKA after the diagnosis of type 1 diabetes by age-at-DKA groups.

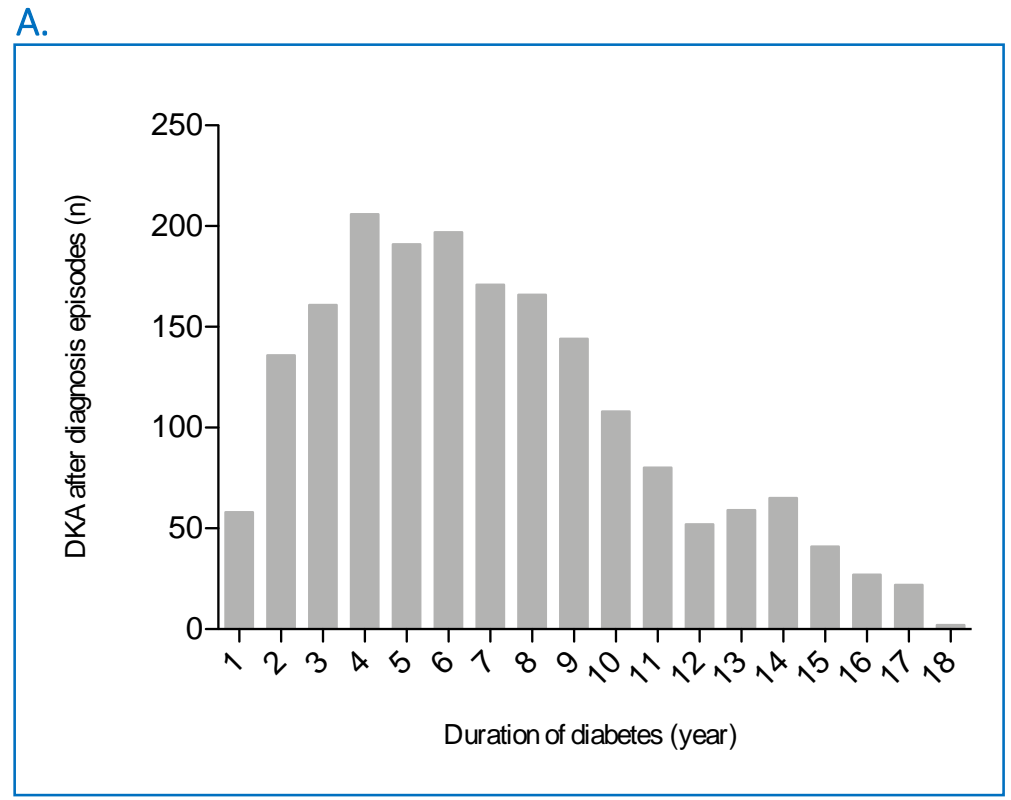

B.

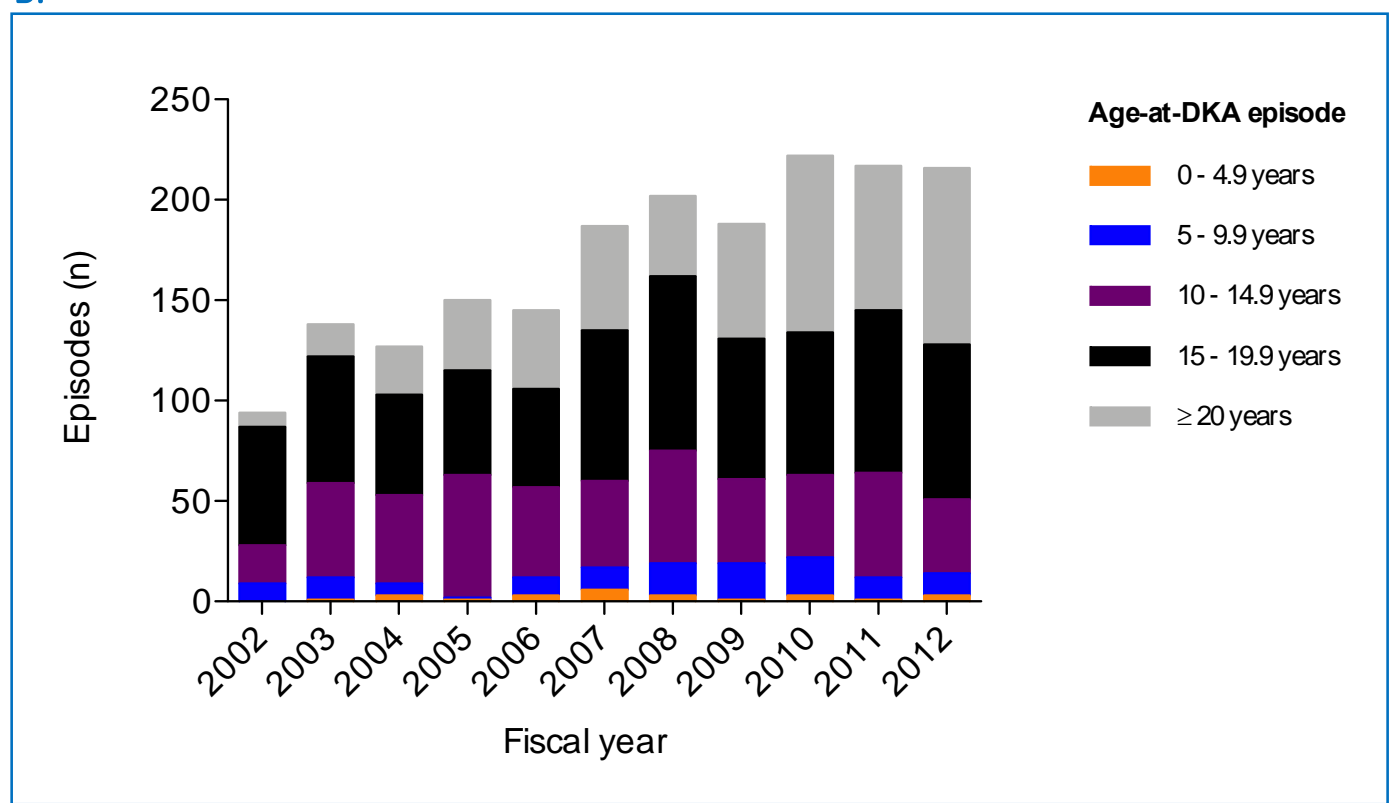


c.

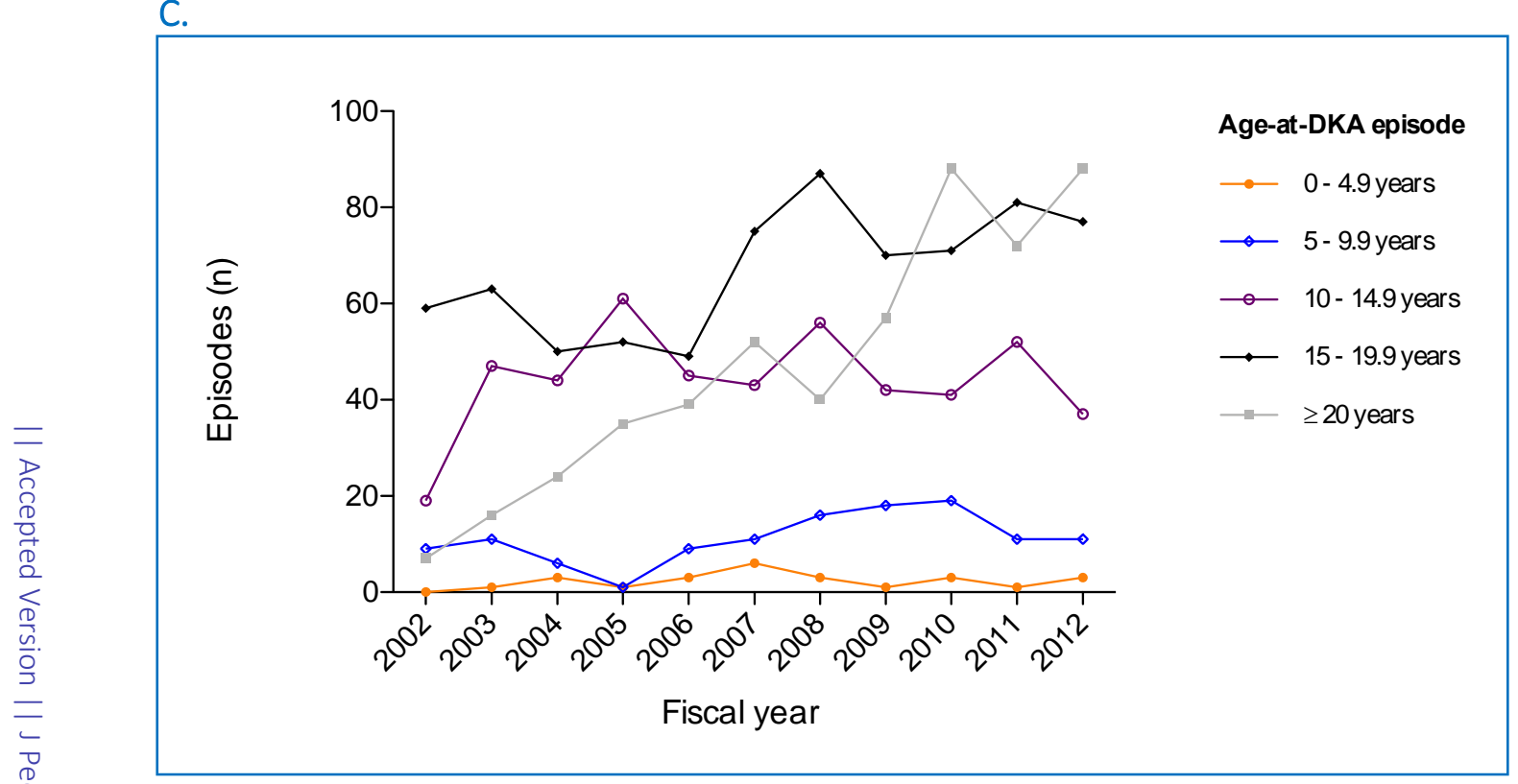


Figure 3. A. Number of prevalent cases of type 1 diabetes and number of episodes of DKA after the diagnosis of type 1 diabetes in British Columbia, Canada; B. Incidence of DKA after the diagnosis of type 1 diabetes by sex; and C. by age-at-DKA episode.

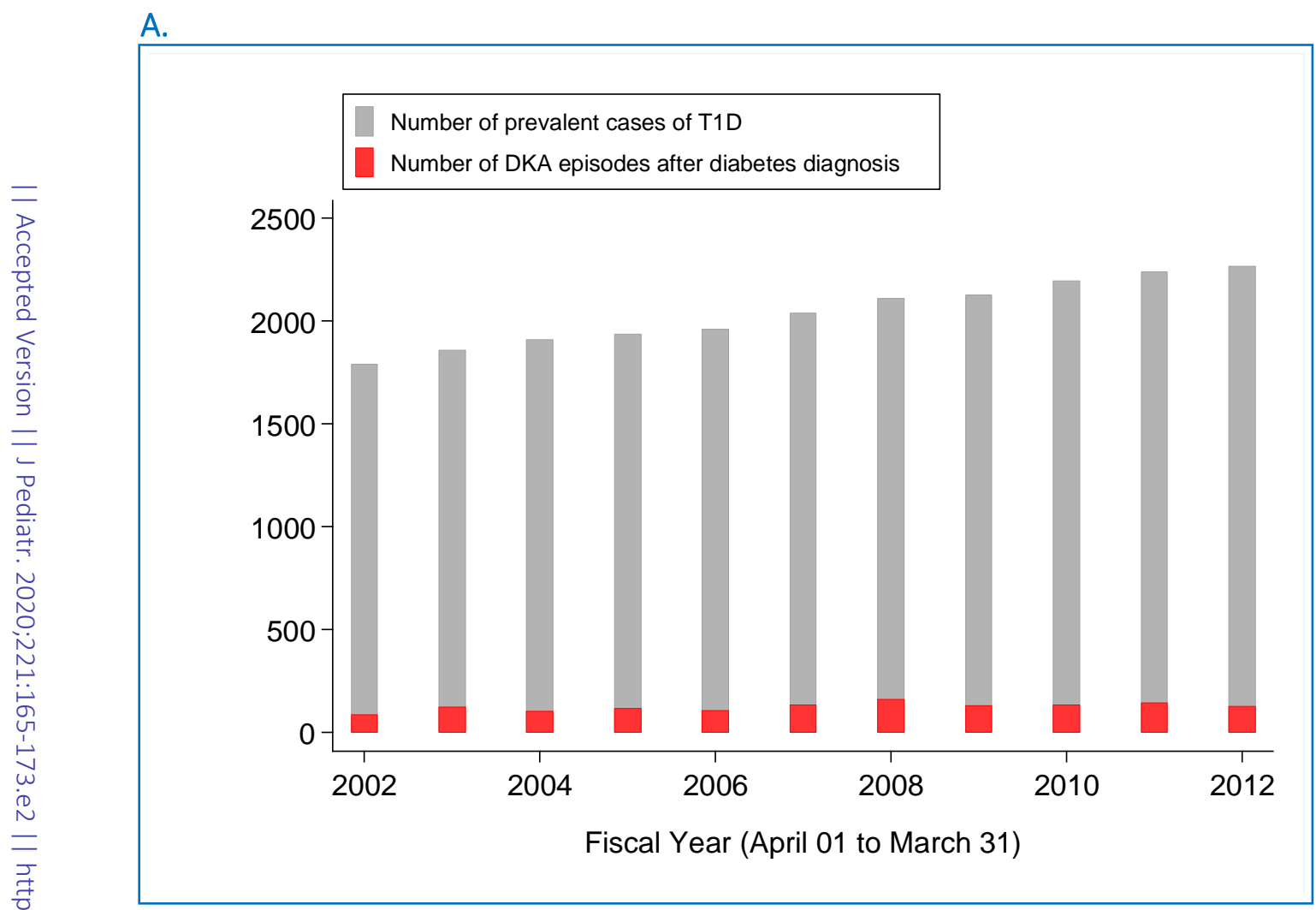


B.

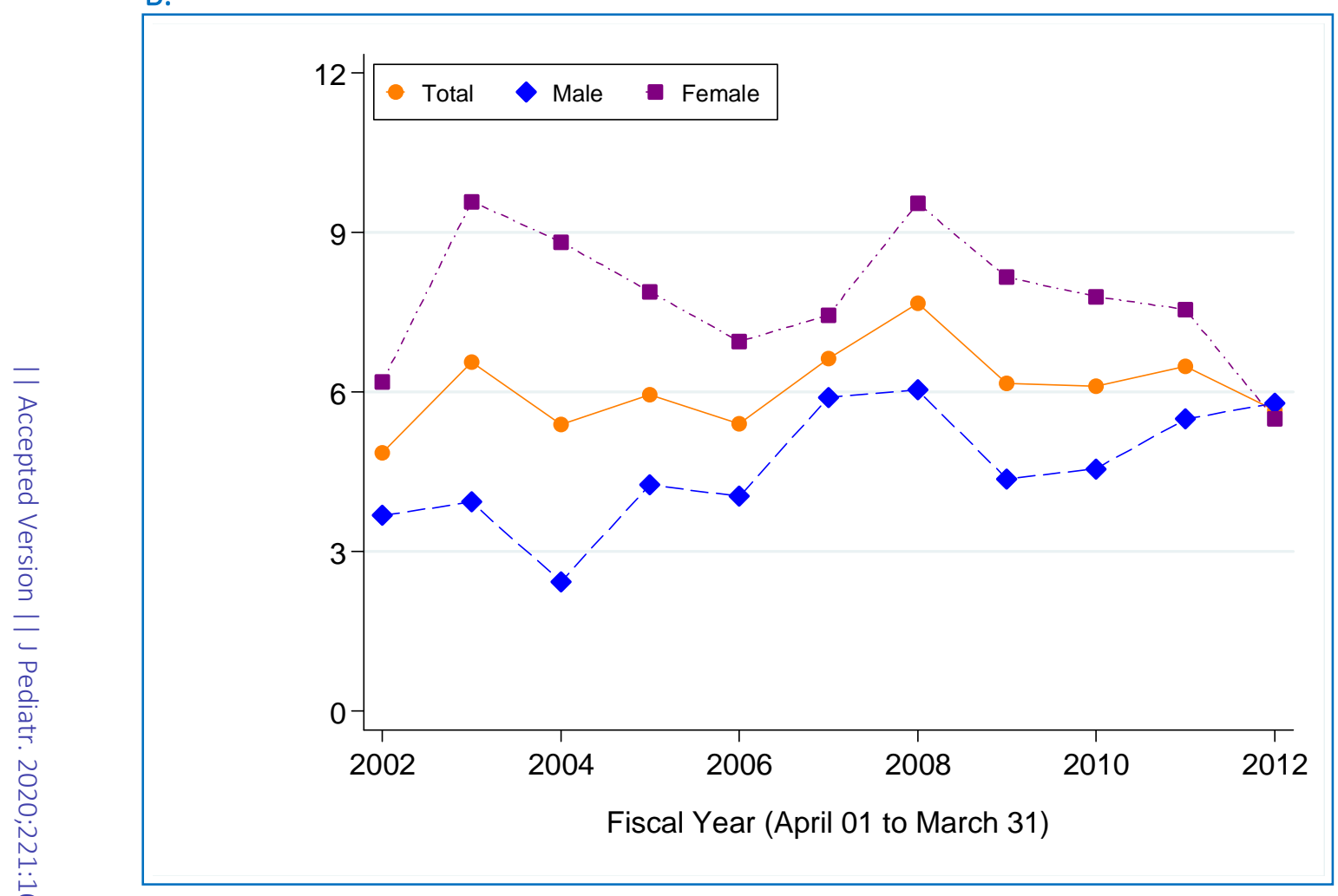

c.

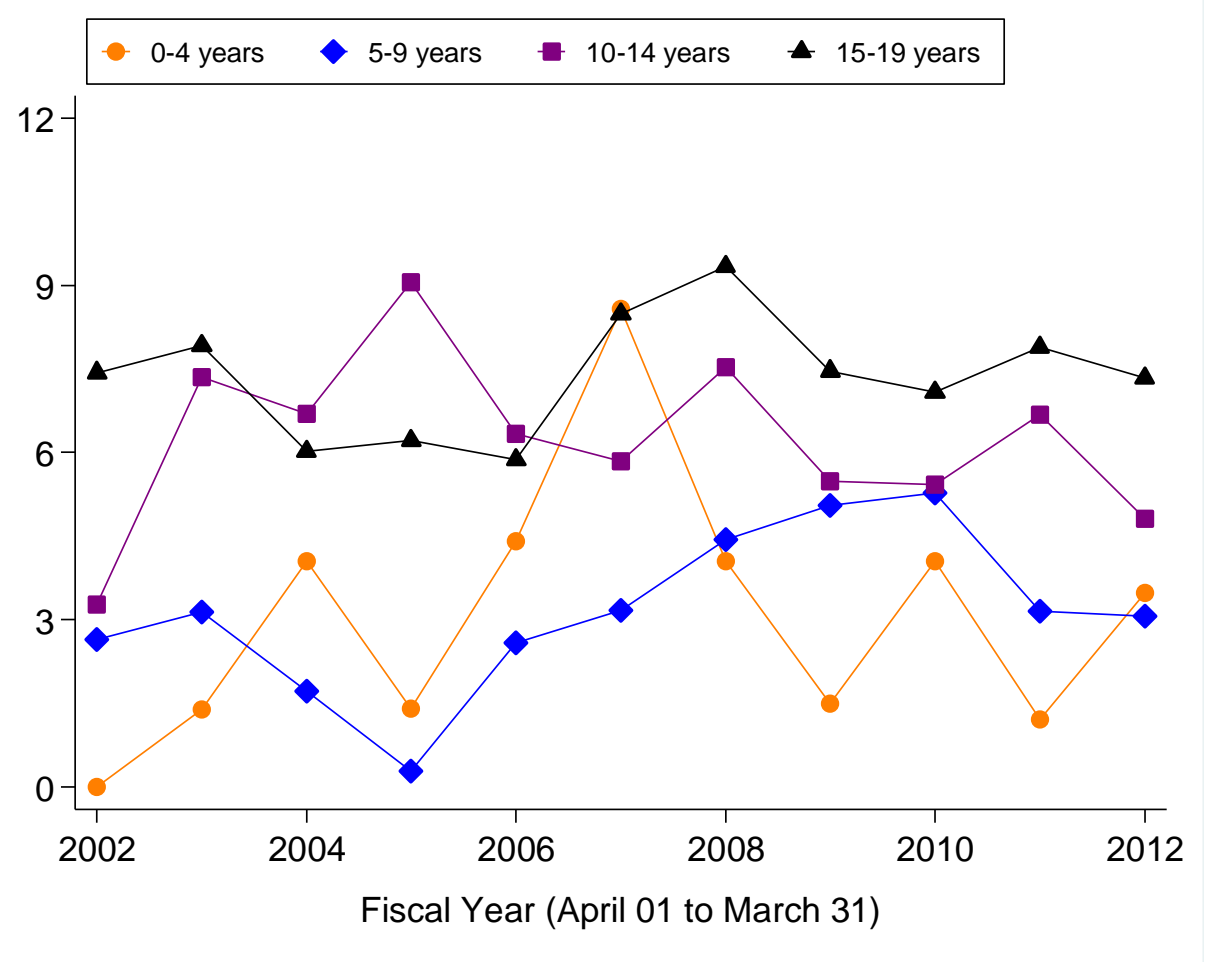

